\title{
Chromosomes and Centrosomes-Team Players in Cell Division
}

\author{
Ronald L. Huston \\ Department of Mechanical and Materials Engineering, University of Cincinnati, Cincinnati, OH, USA \\ Email: ron.huston@uc.edu
}

How to cite this paper: Huston, R.L. (2020) Chromosomes and Centrosomes-Team Players in Cell Division. Advances in Bioscience and Biotechnology, 11, 1-5. https://doi.org/10.4236/abb.2020.111001

Received: December 17, 2019

Accepted: January 16, 2020

Published: January 19, 2020

Copyright $\odot 2020$ by author(s) and Scientific Research Publishing Inc. This work is licensed under the Creative Commons Attribution International License (CC BY 4.0).

http://creativecommons.org/licenses/by/4.0/

\begin{abstract}
This paper provides a mid-level description of cell division and duplication. The focus is on the roles by the chromosomes, centrosomes, microtubules and the kinetochores. The emphasis is on the mechanical activity and the resulting physical developments. The paper also provides, in its discussion, the harmful effects occurring when duplication procedures go awry. This often leads to unwanted duplication and possibly cancer.
\end{abstract}

\section{Keywords}

Chromosome, Centrosome, Centriole, Mitosis

\section{Introduction}

In a recent paper by Antovin and Neuman [1], it is stated that the basic mechanism of chromosome expansion and retraction is not yet well understood. Similarly, full knowledge of the behavior of centrioles is yet to be well understood.

Interestingly, although the names are similar (i.e. "chromosome and centrosome"), their positions and functions differ.

During cell division ("mitosis"), the chromosome and centrosome are connected by perpendicular strands: microtubules and kinetochores, forming a local checkered appearance. The microtubules are connected from the kinetochores and back to the centrosome. The kinetochores remain anchored to the chromosome.

Mitosis occurs via tension in the microtubules between the centrosome and the chromosome. Also, as a result of the mitosis, the nucleus diameter shortens. During mitosis, each half of the separating nucleus takes with it half of the cytoplasm (the remainder of the cell).

The balance of the paper is divided into four sections with the first of these 
describing the chromosome and the next describing the centrosome. The third section discusses mitosis, and the final section provides concluding remarks and a brief presentation of how procedural errors can occur.

\section{Chromosome}

Figure 1 provides a sketch of a chromosome.

It is symmetric about its long end, and consists of four arms called "chromatids" or alternatively, two identical pairs called "sister chromatids". However, the arms are not the same length, with the shorter ones called the "p-arms" and the longer " $\mathrm{q}$-arms".

When the chromosome has the configuration of Figure 1, it consists of condensed DNA.

The centromere is the source for emitted kinetochores. These are strands seeking to unite with microtubules on the nucleus surface. The anchor for the kinetochores remains with the chromosome.

Chromosomes are designed to divide and in this sense they may be viewed as the "zipper" of the cell.

\section{Centrosome}

The centrosome consists of a negatively-charged mound of layered proteins covering the centrioles at the core. Figure 2 provides a sketch of a model of the centriole.

From afar, the centrioles appear as perpendicular cylinders with one of the cylinders attached at the base of the other. A closer look, however, shows that the centriole cylinders consist of microtubules.

The centriole dimensions show them to be relatively short cylinders: approximately 400 to $500 \mu \mathrm{m}$ long and $200 \mu \mathrm{m}$ in diameter [2] [3].

When a cell is about to divide and enter into mitosis, the centrioles duplicate themselves, forming two pairs.

The centrioles and DNA are the only two organelles which duplicate themselves and this duplication occurs at the same time [4]-[9].

The two pair of centrioles then separate. One of the pair, the "elder" (or "mother") pair remains in place while the other pair moves about the nucleus to the diametrically opposite side. This is represented in Figure 3.

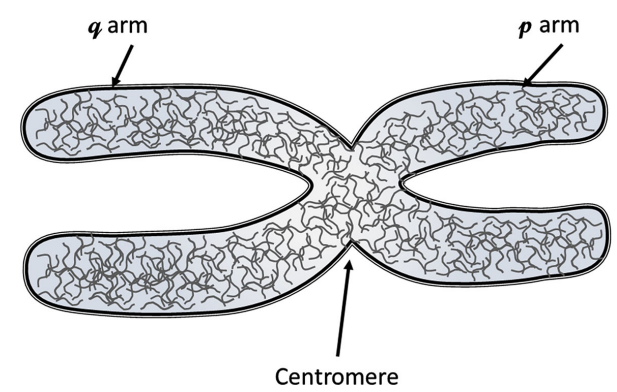

Figure 1. A sketch of a chromosome. 


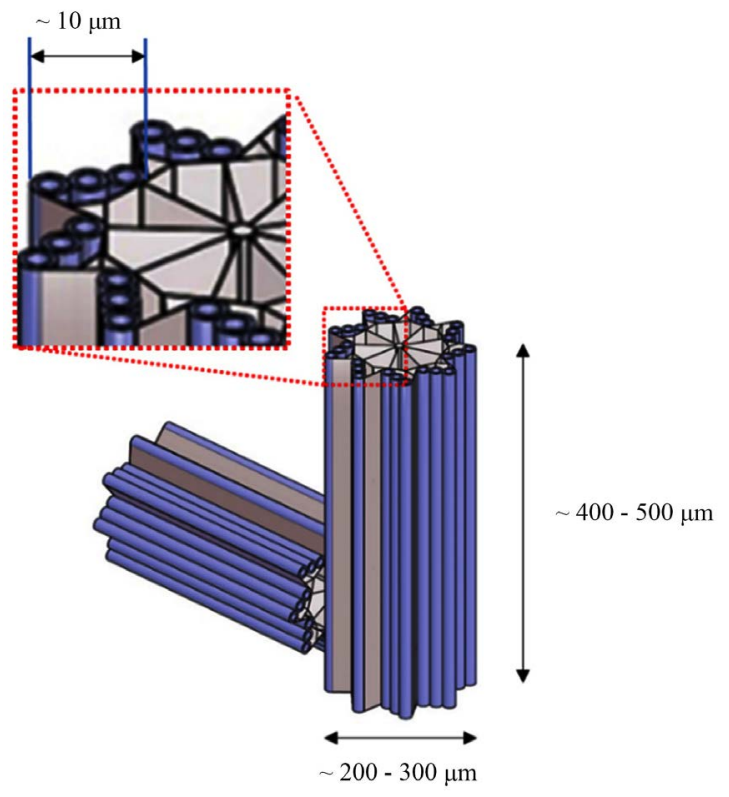

Figure 2. Centriole model.

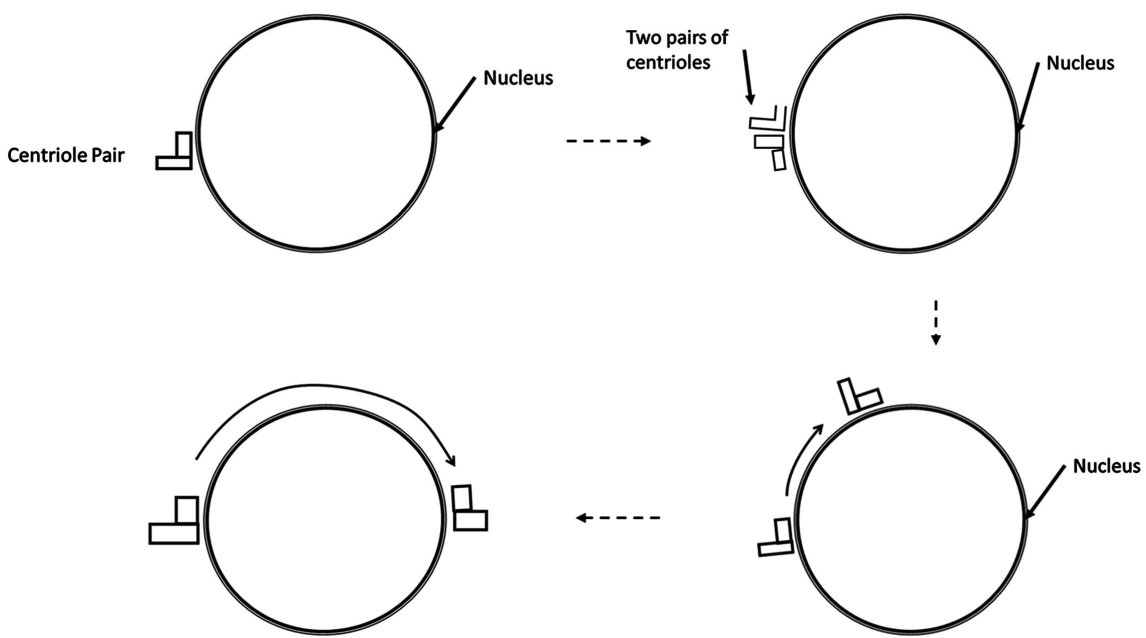

Figure 3. Movement of the daughter centriole about the nucleus.

The movement of the centriole about the nucleus (as represented in Figure 3) is a modeling of the movement in two-dimension. The actual movement is on a three-dimensional path about the nucleus.

Once the centrioles are partitioned and on opposite sides of the nucleus, they begin to accumulate layers of protein until a mound shade body (known as the "centrosome") occurs.

The centrosome houses the beginning of the microtubule strands; thus the centrosome is also known as the microtubule organizing center (MTOC).

\section{Mitosis}

The microtubules emerge from the centrosome across the nucleus surface toward the center and consequently toward the chromosome. At the same time, 
the chromosome sends out strands of its own, known as kinetochores. The kinetochores seek to unite with the microtubules with their shafts being perpendicular. Locally, near the chromosome is a checkered grid.

As this procedure is occurring, the centrosome and chromosome are connected primarily by the microtubules. With the centrosome being anchored on one side of the nucleus, and the chromosome designed to split, the cell separation is begun, with the separation occurring at the chromosome.

As the gap, due to the chromosome split, widens, the single cell is becoming two cells. In this process, the chromosome acts like a zipper, opening the nucleus in two.

Once the nucleus is separated, each part divides the remaining part of the cell (the "cytoplasm"). The cell division is then completed [10].

\section{Discussion \& Conclusions}

The foregoing paragraphs describe the usual events of cell separation and duplication. The most active event in the centrosome is pulling on the chromosome via the microtubules during mitosis. The microtubules can do this via their checkered like attachment to the kinetochores. This pulls the chromosome apart along its lengthwise line of symmetry similar to the opening of a zipper-a new modeling of the separation.

To carry the zipper analogy further, there are lines when a zipper comes apart in the middle and it then becomes ineffective as a fastening device.

Similarly, if the chromosome does not divide along its line of symmetry, it may be separated into several parts, several organelles, or even tumors, can develop.

Irregularities more frequently occur due to an excess of centrioles at both the centrosome and the centrosome-chromosome connection.

It has long been known that tumors possess supernumerary centrioles [11] [12] [13] [14] [15]. Since the centrioles are at the center of the centrosomes, if there are multiple centrosomes pulling on the chromosomes, the result will be a multipart, broken chromosome leading in turn to multipart cell division, and in turn, to tumorigenesis.

Finally, the prevention of tumors is found in having cells with normal division and duplication as described herein.

By an enhanced reading of the references, the majority of the foregoing statements and observations can also be obtained. They are stated herein for a concise summary.

\section{Acknowledgements}

Partial funding support for the research has been generously provided by the Schafer for centrioles research, and is sincerely appreciated.

\section{Conflicts of Interest}

The author declares no conflicts of interest regarding the publication of this paper. 


\section{References}

[1] Antonin, W. and Neumann, H. (2016) Chromosome Condensation and Decondensation during Mitosis. Current Opinion in Cell Biology, 40, 15-22. https://doi.org/10.1016/j.ceb.2016.01.013

[2] Lange, B.M. and Gull, K. (1996) Structure and Function of the Centriole in Animal Cells: Progress and Questions. Trends in Cell Biology, 6, 348-352. https://doi.org/10.1016/0962-8924(96)10033-7

[3] Doxey, S. (2001) Re-Evaluating Centrosome Function. Nature Reviews Molecular Cell Biology, 2, 688-698. https://doi.org/10.1038/35089575

[4] Lingle, W.L. and Salisbury, J.L. (2000) The Role of the Centrosome in the Development of Malignant Tumors. Current Topics in Developmental Biology, 49, 313-339. https://doi.org/10.1016/S0070-2153(99)49015-5

[5] Piel, M., Meyer, P., Khodjakov, A., Rieder, C.L. and Bornens, M. (2000) The Respective Contribution of the Mother and Daughter Centrioles to Centrosome Activity and Behavior in Vertebrate Cells. Journal of Cell Biology, 149, 317-330. https://doi.org/10.1083/jcb.149.2.317

[6] Brito, D.A., Gouvela, S.M. and Bettencourt-Dias, M. (2012) Deconstructing the Centriole: Structure and Number Control. Current Opinion in Cell Biology, 24, 4-13. https://doi.org/10.1016/j.ceb.2012.01.003

[7] Krämer, A., Neben, K. and Ho, A.D. (2002) Centrosome Replication, Genomic Instability and Cancer. Leukemia, 16, 767-775. https://doi.org/10.1038/sj.leu.2402454

[8] Doxey, S.J. (2001) Centrosomes as Command Centres for Cellular Control. Nature Cell Biology, 3, E105-E108. https://doi.org/10.1038/35074618

[9] Lingle, W.L., Lutz, W.H., Ingle, J.N., Maihle, N.J. and Salisbury, J.L. (1998) Centrosome Hypertrophy in Human Breast Tumors: Implications for Genomic Stability and Cell Polarity. Proceedings of the National Academy of Sciences, 95, 2050-2955. https://doi.org/10.1073/pnas.95.6.2950

[10] Hardin, J., Bertoni, G. and Kleinsmith, L.J. (2015) Becker's World of the Cell. 8th Edition, Pearson Publishing, London, 578.

[11] Godinho, S.A., Kwon, M. and Pellman, D. (2009) Centrosomes and Cancer: How Cancer Cells Divide with Too Many Centrosomes. Cancer Metastasis Review, 28, 85-98. https://doi.org/10.1007/s10555-008-9163-6

[12] Sluder, G. and Nordberg, J.J. (2004) The Good, the Bad, and the Ugly: The Practical Consequences of Centrosome Amplification. Current Opinion in Cell Biology, 16, 49-54. https://doi.org/10.1016/j.ceb.2003.11.006

[13] Tsou, M.F. and Stearns, T. (2006) Mechanism Limiting Centrosome Duplication to Once per Cell Cycle. Nature, 442, 947-951. https://doi.org/10.1038/nature04985

[14] Rajagopalan, H. and Lengauer, C. (2004) Aneuploidy and Cancer. Nature, 432, 338341. https://doi.org/10.1038/nature03099

[15] Lingle, W.L., et al. (2002) Centrosome Amplification Drives Chromosomal Instability in Breast Tumor Development. Proceedings of the National Academy of Sciences (PNAS), 99, 1978-1983. https://doi.org/10.1073/pnas.032479999 